\title{
Exploring Project-Based Teaching for Engaging Students' Mathematical Learning
}

\author{
Raj Kumar Tyata ${ }^{1, *}$, Niroj Dahal ${ }^{2}$, Binod Prasad Pant ${ }^{3}$ and Bal Chandra Luitel ${ }^{4}$ \\ ${ }^{1}$ Aksharaa School, Kathmandu, Nepal, \\ 2,3,4, Kathmandu University School of Education, \\ Department of STEAM Education, Hattiban, Lalitpur, Nepal \\ ${ }^{*}$ Corresponding Author: rajkumar.t@aksharaaschool.edu.np
}

\begin{abstract}
The declining interest of learners in mathematics in the learning process has resulted in poor achievement (Yeh et al., 2019). To get rid of these poor achievements, we explored project-based teaching in four topical areas (e.g., mathematical concepts of coordinate geometry, trigonometry, sequence, and series) in the school mathematics. This paper results from observing changes in engagement of learners in learning mathematics by motivating them through the project-based learning (PBL) guided by two theories - knowledge constitutive interests (Habermas, 1972), and collaborative and cooperative learning under the paradigms of interpretivism and criticalism. In this ethos, PBL is an "engaging and learner-directed approach that provides equal opportunities for students to explore their knowledge and understanding" (Thomas, 2000, p. 12). More specifically, we adopted the 'action research' method with the secondary level students (Grade $I X)$ of one of the institutional schools in their classrooms. The information was collected by observing and recording the changes seen in consecutive seventeen days. The research landed that project-based learning is an appropriate pedagogy for engaged learning. The study revealed that the students were motivated while they got opportunities to interact in the projects. Moreover, the findings show that PBL is helpful to engage the learners through questioning, pair/group discussion, discovery learning, and concept mapping.
\end{abstract}

Keywords: Project-based learning, trigonometry, engaged learning and questioning.

\section{Introduction}

Learning through a project is not new in mathematics. It has been practiced for many years, but in the context of Nepal, it is rare (Dahal, 2013; Dahal, 2020). Moreover, most teachers are still unaware of the PBL pedagogy, and most of them have not used projects to teach mathematics. This might be one of the reasons that mathematics learning is not meaningful and exciting. In recent days, we also faced similar kinds of problems. Learners in the classroom were not motivated to learn mathematics and paid less attention to it. The learners were not interested in solving 
real-life mathematical problems and had very little interaction with the teacher(s). We observed that the learners were highly frustrated with the similar type of learning mathematics from the initial school days. Then we looked for appropriate pedagogies to get rid of these problems. Among many pedagogies, we selected PBL in teaching mathematics, especially trigonometry. We had the opportunity followed by challenges in applying the PBL method in teaching trigonometry. We experienced that it would be much difficult for us to connect all the contents of trigonometry of the textbook to the day-to-day activities. For that reason, we included coordinate geometry as well in the project. Pertaining to the above scenario, one of the narratives of the first author goes as follows:

It was a day of summer in 2017 while the first author was introducing the new concept of mathematics called trigonometry to Grade IX in one of the schools of the Kathmandu Valley. He felt that the students were not interested in learning and not grasping what was taught in the class. They sat quietly most of the time and looked as if they were listening to him and understanding everything. But while using the standard assessment test after completing the unit, the performance of most of the students was below average. This incident made the first author rethink or revisit his own strategies of teaching and learning mathematics. The first author sat alone in the school lobby and thought for a long.

In ten years of teaching experiences, the first author got many opportunities to explore mathematical concepts using manipulative materials through projects and pedagogies for teaching mathematical concepts like sets, algebra, geometry, profit and loss, ratio and proportion, statistics, etc. But got puzzled while teaching coordinate geometry and trigonometric identities to relate with the students' context and life, to use the materials and to make them more interesting. When a student of Grade IX of an institutional school asked him a question, "What is the use of trigonometry in our real life?" in the middle of the class, he was so happy to answer as "We can use trigonometry to find the height and distance of the object as well as there are many uses in the engineering field. Also, the researchers use it for scientific research." Then another student asked "Teacher, I don't want to be an engineer. I aim to be a doctor. So, I don't need to study mathematics, do I?" No sooner had this student finished his question, a third question echoed in the class "Sir, what are the uses of trigonometric identities and the complex process of proving it?" He did not have an answer to this question. The first author managed somehow by saying "It helps to increase your logical power, every mathematical skill and it's good to have more knowledge of those 
contents".

After the class, the first author shared his opportunities to explore the issue(s) raised to the second, third and fourth authors. Then we shared our thoughts and concluded that 'logical power' was also developed by many other interesting, funny, and creative games in mathematics. So, to get clear ideas and improve the students' critical thinking, we started inquiring about the issue with many other coteachers and facilitators. The first author interacted with some teachers who were directly engaged in teaching trigonometry at the secondary level. But he did not get satisfactory responses from them.

Moreover, most of them replied that trigonometry could be improved by practicing; it is not so much linked with the children's real-life context. In this changing scenario, the first author intended to explore the contextual learning of trigonometry using projects with the support of second, third, and fourth authors. While searching for possible teaching and learning methods of mathematics, the first impression was implementing PBL method as it is a child-centered method and engages students in meaningful learning (Goodman, 2010). We thought setting up the project would help the students connect the trigonometric concepts with their everyday life activities.

Likewise, the purpose of this study was to explore the PBL in teaching mathematics at the secondary level on some of the topics, namely coordinate geometry, trigonometry, sequence, and series. The pedagogical perspective helps to understand the concepts of coordinate geometry and trigonometry by engaging students to construct knowledge relating to their real-life experiences and practices to make learning more interesting and fun guided by the research question--how can we engage learners in the meaning-making process while dealing with coordinate geometry and trigonometry through project-based learning?

\section{Supporting Literature}

Project-Based Learning. PBL as emerging pedagogy can address sociocultural and contextually relevant mathematics learning with meaningful and engaged learning. This approach has helped shift the academic rigor to authentic and meaningful learning. Besides, PBL connects mathematics with other disciplines (Moursund, 1999) to foster the students' creativity and innovative skills by socializing with the learners' community. Likewise, it develops researching habits of students through the identification of the pivots. This research paper explored students' knowledge in coordinate geometry and trigonometry collaborating with other disciplines. In this line, Goodman (2010, p. 5) argues, "PBL is an instructional approach built upon learning activities and real tasks that have brought challenges for students to solve". It allows students to reflect upon their ideas and opinions 
and make decisions that generally affect project outcomes and learning processes. So, while working with the project, students get opportunities to relate coordinate geometry and trigonometry with contexts and then interpret and analyze with the eye of culture. And it triggers ideas and opinions to draw consensual understanding (Tyata, 2018). Learners will be able to identify the required information for the completion of projects into three different types -good-to-know information, need-toknow information, and not-to-know information as categorized by the Department of Labour (DOL, 2018).

Further, PBL pedagogy is based on the constructivist theory, an instructional approach built upon learning activities and real tasks that have posed challenges for students to solve problems. It helps in strengthening the understanding of students through interaction, communication, and collaboration with fellow learners. PBL grabs students' attention through the use of inquiry to solve real-world issues or questions. It helps in developing 21st-century skills, a fusion of the three Rs (reading, writing, and arithmetic) with the four Cs (communication, collaboration, creativity, and critical thinking) (Goodman, 2010). PBL consists of five key features, namely a driving question, participation in authentic and situated inquiry, engagement in collaborative activities, scaffold with learning technologies and set of tangible products to address the driving question (Blimenfeld et al., 1991; Krajcik et al., 1994; Krajcik et al., 2002 as cited in Krajcik \& Blumenfeld, 2006). These features made PBL a strong approach to teaching and learning.

Having discussed some of the pedagogical perspectives with regard to teaching mathematics, questions arise as to whether PBL works in improving learning coordinate geometry and trigonometry or not. Research shows that after forty years of practice of PBL in learning, it is found that it is more effective, resultant, practical and serviceable than any traditional way of instruction. Goodman (2010) also claims that it helps in improving the mastery of $21^{\text {st }}$-century skills and especially effective for low-achieving learners. In this regard, this research paper forecasts that it might also help learn coordinate geometry and trigonometry to the secondary level school children. Similarly, it might be effective in learning coordinate geometry through PBL because it shifts the role of the learners to that of the teachers, teachers to coaches involving parents and community in learning. Improving learners' learning strategies and thinking skills, PBL enhances students' learning behaviours, such as learning to learn, lifelong learning, active learning, and cooperative learning.

Project-Based Learning in Mathematics. PBL in mathematics involves introducing challenging problems that get learners' creativity (Quist, 2018). As the PBL demands real authentic contexts and problems, projects in mathematics 
also need to be developed in real contexts incorporating challenging and authentic problems from the real world. During the projects, students gather information on the projects and decide how to approach finding solutions. By applying an interdisciplinary approach to the problem, learners decide the wise use of obtained knowledge to communicate results effectively. Mathematical projects often pose complex problems based on mathematics, allowing the learner to think critically to find solutions (Pant, 2015). In this scenario, PBL may be one of the effective tools to enhance the students' learning in that it paves the way for learning through selfreflection. In collaboration with the culture, co-learners and their prior knowledge, learners will get an opportunity of thinking upon their learning. Since PBL provides an environment for critical analysis of mathematical concepts, it might be one of the pillars of mathematical education.

\section{Theoretical Referents}

Knowledge Constitutive Interest. Human nature is self-oriented and so is the process of constructing knowledge. From infancy to adulthood, they behave according to their interests. They get engaged mostly in such an activity where they get benefited. According to Habermas (1972), human interest is classified into three different categories namely technical, practical, and emancipatory interest. Knowledge constructed through the technical interest is objective knowledge that takes mathematical learning isolated from the practical implementation in human life. However, practical interest addresses the human experiences and their cultural practices of mathematics learning and connects mathematics to real life, whereas empowering learners and engaging them in the thinking process motivates children to learn mathematics concerning context and communal practices, it also helps inform the society about the fallible and corrigible nature of mathematics where mathematical knowledge incorporates proofs and concepts of mathematics are eternally open to revision (Ernest, 2001). This research aims to develop practical ways to provide a suitable environment for critical thinking to empower learners to learn mathematics through the application of projects based on learners' contextual and real-life practices. Being emancipated for the critical discourse of trigonometric relations and human mathematical experiences, learners will get opportunities to connect mathematics with hands-on activities.

Cooperative and Collaborative Learning. While talking about PBL, cooperation between learners and teachers is a must which can be enhanced through interaction and dialogue. Questioning is one of the ways of dialogue which makes students participate actively in productive interaction (Dahal, 2017), stand on a side of the argument, and throw their opinion on the topics. This also helps develop skills of communication and collaboration which are key requirements for the PBL (Tyata, 
2018). Most of the traditional ways of teaching and learning exist as a transferring of knowledge from teacher's head to the learner's head, which Freire (1972) discusses as a 'banking system of knowledge'. In opposition to this view of acquiring knowledge, collaborative and cooperative learning emphasizes the 'shared knowledge' motivating on the construction of knowledge through pair discussion, group discussion, and active interaction. During the initial days of the first author's teaching career, he had a good experience of transmitting knowledge through the 'one-way flow of information'. The first author used to stand in front of the classroom and instruct students to follow him (copy the solution of routine mathematical problems and procedure) that he thought was the best way and should be applied by the learners. They rarely asked him any question about his process, pros and cons, and the reasons behind using that particular method to solve mathematical problems. In the view of the learners, the teacher was the super-powered god, they knew everything, what they said was true and students could not raise questions against them. This view of accepting knowledge from the teacher has been in practice since ancient times, from 'Gurukul Shikchhya', in Nepal. In addition to this, the first author frequently used to say "Why fear when Mini-Library is here?" which assures them that the teachers are Almighty. In that context, pair sharing, group discussion, and collaborative learning could not be imagined. Students would not get a suitable environment to learn by sharing their understanding.

\section{Research Methodology}

This study was conducted on the professional problems that we faced as practitioners to improve practices and to find the solution to the real-life problems themselves. For this study, we have chosen 'action research' as an appropriate method to be applied in teaching mathematics as we will get enough opportunities to collaborate with participants in the normal setting for meaningful teaching and learning process. The interacting spiral proposed by Stringer (2007) for 'action research' clarifies the cycle in the continuous process of 'look', 'think', and 'act', which may repeat over and otherwise. At first, the researcher(s) critically observes the situation to identify the problem, which we call problematizing by critical observation. Then we think upon the problems to locate possible solutions making plans for systematically solving them and finally, we make valid conclusions for the solution, execute the plan in the real scenario. This completes a cycle. The 'action research' spiral proposed by Kemmis and McTaggart (1988) includes three different stages, starting to 'plan', then 'act and observe' and finally 'reflect'. According to the model, firstly, we prepared an action plan for fifteen days to overcome the problem. After that, the plan was executed in the classroom setting in an institutional school (Grade IX) of Kathmandu. And finally, we reflected upon the finding and 
observations collected from the practice teaching.

More so, action research is an inquiry that enables practitioners to investigate and evaluate their work (McNiff \& Whitehead, 2006). It answers questions like, 'What am I doing?', 'What do I need to improve?', 'How do I improve it?', etc. Action research can be conducted in four different ways: individual teacher research, collaborative action research, school-wise research, and district-wise research (Frerrance, 2000), among which this study belongs to the teacher(s) action research. For conducting action research, Creswell (2012) suggests some major steps be incorporated by identification of the problem, action plan, data collection, analysis of data and reflection \& plan for future action. The research is conducted upon the students of grade IX of an institutional secondary school from the Kathmandu Valley. According to the new education structure of Nepal, this grade is taken as the starting grade of a secondary level where they have a choice of additional mathematics. Also, the participants learn additional mathematics for the first time in their schooling, according to the curriculum of Nepal prepared by the curriculum development centre. The study included different projects concerned with coordinate geometry and trigonometry, which lead students to collaborate, interact, and research the areas as guided in the project guidelines. Maintaining the role of learners and tutors and relation between them, the study took place in the natural setting.

\section{Discussion of the Findings}

Based on the developed research question and constructed methodological map, this section presents the significant findings of our research as summarized below.

\section{PBL Promotes Engaged Learning Through Questioning}

On July $29^{\text {th }}, 2018$, the first day of the project, while experimenting with the first project to the twenty-nine participants of grade IX from the school, after explaining the project, the plan, and its objectives, the first author asked students a question as a class starter. And the following is what

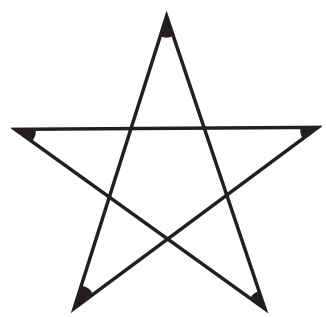
followed.

Teacher researcher: What is the sum of interior angles (marked angles) of Starshape?

Student I: $360^{\circ}$ degrees!

Student II: No, no..... 400 degrees!

Student III: No, it's not. It's $540^{\circ}$ degrees

And so on ...

Most of the students started estimating and guessing, whereas some of them started having discussion with their friends, and some others were trying to calculate 
themselves in the rough paper. The first author waved his head against their answer. After some minutes, they started shouting.

Student: What is the answer, sir?

Teacher: You won't believe; the sum is surprising. Even I got surprised when I found it.

Student: What is that answer, Sir?

Teacher: You ought to use the theorem; the sum of two interior angles of the triangle is equal to the opposite exterior angle.

Student I: Oh, I got it, $180^{\circ}$

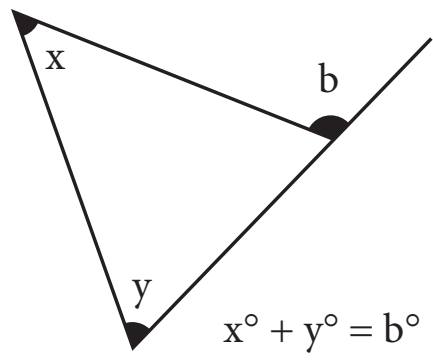

Student II: How? How?, she screamed.

Student I: I just guessed. It may be due to the sum of interior angles of the triangle, said with a smiley face.

Teacher: Although you don't know the reason, your answer is correct.

Yeah.........., students screamed.

Then the first author explained by drawing the adjoining figures and the figures on the next page on the board, first about the theorem and second about the sum of star-shaped interior angles.

From that, the learners get, $\mathrm{x}+\mathrm{y}=\mathrm{b}$ and $\mathrm{m}+\mathrm{n}=\mathrm{c}$.

Which gives, $\mathrm{a}+\mathrm{b}+\mathrm{c}=180^{\circ}$.

They were so surprised to hear that. Everyone started to look at each other's faces shockingly. And the first author thought it is an example of an 'engaged classroom with a questioning'. On the first day itself, the learner took part in a discussion about the mathematical ideas. Though the content was coordinate geometry, the question raised at the beginning of the project energized and made all curious about the project. At the beginning of my teaching career, the first author did not find students participating in the learning process. They were passive recipients of knowledge, whatever teacher explained while solving problems, they used to listen and note down in their notebook in a similar manner to Freire's (1993) claim in his book, the pedagogy of the Oppressed as banking knowledge. The teacher kept talking and the students were simply the passive listeners. But after all these efforts, the students started to answer the teacher's queries and participate in the classroom activities and thus the class started functioning in a two-way communication module. Initially, the learners deposited knowledge without being aware of the contextual and practical use of it in life. They seemed isolated in the group and have no interaction and collaboration among friends. And even the method of learning was transmitting the facts from one cognition to others. In contrast, the incident narrated above indicates that the learners were participating actively in the classroom. They 
exhibited cooperative and collaborative behaviors while questioning and answering (Dahal, 2017). They were busy constructing knowledge by practicing a healthier learning environment which is more tilted to the practical interest of Habermas (1972).

In addition to this, we found that 'questioning' is a better choice for engaging the students in learning. The learners get alert while the teacher(s) throws questions to them. They were compelled to think about the 'issues raised in the question' and get involved in the learning process. On the third day of the project (1st August 2018), a girl surprised the first author by answering a question related to the slope of the line on the graph. When he was presenting the slope of a straight-line using ICT tools in the classroom, the students were making note of important points from the presentation. The first author was in the middle of the presentation, suddenly, he asked students a question 'What is a rise and run of the line in this figure?' to Osheen (a learner, pseudo-name), she stood from her place looking at the adjoining figure and answered the question. Rise $=4$ and run $=6$. She was tagged as a low achiever who never interacted in the class and was considered as a passive recipient of knowledge by all teachers. Also, in the first author's book of mind, she was a submissive student; she never answered questions since the beginning of the academic year. But she answered questions after a few days of carrying out the project. This shows that a teacher has art to drive students to construct knowledge by motivating them to engage in questioning actively.

After the interaction, another child seemed curious to know: "Can the slope be negative?" The class was silent for a few seconds. No-one was sure about it. They started looking at each other's faces, seeking an answer. The first author broke the silence by questioning back "What is the slope of the line which makes $135^{\circ}$ degrees angle with positive $x$-axis?" One of the students, so-called brilliant child, stood and said, "negative one, sir (-1)". Then I asked, "So, what do you think now? Can the slope of the line be negative?" They shook their head in support of the statement. In this case, we found the learners started probing questions and shared answers in the classroom. Similarly, learners were showing their interest and eagerness to learn by asking questions (Dahal, 2017). They were engaging themselves by stirring their misunderstanding and misconceptions through questioning, which is highly effective for engaging students in learning (Caram \& Davis, 2005). On the eleventh day of the project (14th August 2018), a child saw sub-units in the degree system and grade system for measuring angles like minutes (') and seconds ("). Then she asked, 'How many minutes is one radian?' which opened the space for thought process in the classroom. All the learners were pondering inside them for fractions of minutes. There are no sub-units in the radian measure, a child replied. 
And the first author thought this is what collaborative learning means.

According to Caram and Devis (2005), there are two significant ways to generate questions: ' Teacher generated questioning' and 'students generated questioning'. On the first method, the teacher starts questioning the learners, whereas on the second, students put questions. We found both the parties involved in both the ways of questioning. Two of the examples above incorporate 'teacher generated questioning' and the other two include 'student-generated questioning'. Nevertheless, the mode of questioning also has been improved/changed in the classroom. Among the six different methods of Socratic questioning (1. questions that required clarification, 2. questions probing assumptions, 3. questions probing reasoning and evidence, 4 . question probing perspective, 5 . questions probing implications, 6. questions about the question (Paul \& Elder, 2007 as cited in Le \& Huse, 2016), we had experienced the first (question for clarification) and sixth (questions about question) types have only been raised before. For example, 'What is the answer to this question? How to solve this? How to move forward after this? I don't know, please teach me, etc.' However, during the project, the learner started to ask questions like ' Is this solution correct? We need to find ...(this)..... for ....... (that)...... Isn't it? (Question probing reasoning and evidence, perspective). In the past, they used to copy teacher's procedural knowledge in their cognition and seek the support of teacher for solving problems, they had a habit of giving up when the problems are difficult and new for them, whereas it has been altered, they tried to solve problems themselves and just seek clues to solve.

It may be the project that we applied which gave rise to change the way of asking questions in the classroom. In the first author's observation, learners barely asked questions in the classroom in previous days. After applying the project, we found students asking questions and they changed the nature of questioning. This might be due to the projects that the first author applied in the classroom or due to behavioural changes in the classroom teaching such as cooperative behaviours, loose-control and suggesting ideas. Before the first author used hard control in the classroom (Taylor, 1998), who did not give any space for interaction in the classroom. Learners did not get the opportunity to share their understanding with their friends in the class. The class with pin-drop silence was regarded as the best class. But while applying the project, this view has been changed to an active and interactive class. We must give space to learners for discussion in the class and time for sharing and interacting with friends. In this case, PBL has promoted the teaching and learning methodology of both learners and teachers.

Similarly, students actively engage with projects which provide real-world relevance for learning (BIE, 2018) and they create meaning through cooperative 
and collaborative learning. While learners raise questions, they involve in active interaction with their co-learners and tutor. They learn to listen to their friends and their friends learn to listen to them in turn. So, questioning gives rise to dialogues between two different bodies. As a result, they construct knowledge working hand in hand. According to Garner (1993), students learn best when they are actively engaged in learning and questioning and is one of the ways of engaging actively in the context. At the same time, learners' self-awareness on constructing knowledge emancipates and alerts them for truth and falsity of the subject thinking better options. Students practice a higher level of constructing knowledge that is the practical interest in constructing knowledge proposed by Habermas (1972). Moreover, questioning forces learners to examine the subject critically and steer inside the mind for better choices. The ideas proposed by the participants in a discussion show both positivity and negativity of the issues; as a result, learners get motivated for the right and better choices. This idea of critical pedagogy is possible through the active involvement of learners in the learning process, which is being motivated by questioning. Freire's (1993) 'problem-posing method' over 'banking method" also aim at making learners engaged in the learning process to construct knowledge by problematizing. In this regard, PBL engaged the learners and helped them construct knowledge through questioning.

\section{PBL Endorses Engaged Learning Through Pair/Group Works}

It was Sunday morning (19th August 2018), the first author had planned to collect facts and information about the assigned topics. Students were supposed to go to the computer lab or library to search for their assigned topic. The first author had listed several different issues related to trigonometry and let students research it on the internet using the computer lab and reference books available in the library. The students of grade IX were divided into six different groups (with $4 / 5$ members in a group) assigning six different titles to research; namely i) System of measuring angles, ii) Relation between these systems, iii) One radian and A radian is a constant angle, iv) Relation between arc, radius, and angle, v) Values of trigonometric ratios and vi) CAST relation (transformation relation for angle in trigonometry) in trigonometry. Each group picked up a topic from six different chits. They were assigned 15 minutes for researching, five minutes for transition time and 20 minutes for time 'sharing'. They started searching about the topic; some went to the library, some in the computer lab. As the computer lab was next to the library, it was easy for the first author to observe students in both the rooms; besides, the computer teacher helped by monitoring students. After they finished their research work, the first author along with students returned to the class and started sharing. Two students from each group shared their findings, while one group was sharing, other group 
members put forward their queries. One of the dialogues between different members was interesting and catchy to all the participants. The conversation was about the theorem: A radian is a constant angle.

Paul, one of the students, explained about 'one-radian' showing diagram on the News-print paper. Then proved a radian as a constant angle. In between, he used the ratio and $\frac{\mathrm{r}}{\pi \mathrm{r}}=\frac{1^{\mathrm{c}}}{180}$, where another student (Prosiya) got stuck. Maybe she could not understand the ideas explained by Paul. So, she raised the question, and the conversation began.

Prosiya: I could understand $\overline{\overline{\mathrm{ABC}}}=\frac{\mathrm{r}}{\pi \mathrm{r}}$. But how did you obtain that relation of arc and angle?

Paul: The first one is the ratio of arcs and the second one is the ratio of angles since both are ratios, they are equal.

Prosiya: What does it mean?

Paul: Two different ratios are equal.

Prosiya: How are they equal?

Paul: Because they are ratios, and they are always equal.

Most of the students who were listening to that conversation were quite dissatisfied with the answer of Paul. The first author saw everyone looking astoundingly at Paul. Then the third student interrupted their discussion.

Pratistha: How can all ratios be equal? There are so many ratios that are not equal such as $1 / 2$ and $3 / 8$ are not equal. Now, Paul got puzzled and asked help from his other group members to answer that question. Even the group members were not able to answer the reason behind it so he was helpless. Then the first author gave a hint, Check the relation between angle and arc in the given figure. What happens if the angle increases? Then they started talking with friends about it and a boy from the third group said, "If the angle increases, the length of the arc also increases, so angle and length of the arc are directly proportional." Immediately after that, a girl from the fifth group asked, "You found $1^{\mathrm{c}}=\frac{\pi}{180}$, how is one radian constant?" Then Paul answered, " $\pi=3.1416$ which is a constant value, that is $\pi / 180$ is also constant. So, a radian is a constant". This ends the conversation and makes a consensual understanding that 'a radian is a constant angle.'

The above discussion and interaction of students in groups and among groups reveals that students are participating actively in the class. They are arguing logically about the ideas in two different ways. First, inside themselves, self-arguing compared with prior knowledge and present experience and outside, that is, with friends, their own knowledge and views of other members. Having discussion with friends and sharing thoughts and experiences with pair and group members helped them develop a consensual understanding of the subject. Manning and 
Payne (1993) urge that the social-constructivist approach involves the processes of social interaction and application of knowledge (Carruthers \& Worthington, 2006) and practical and emancipatory interest of Habermas (1972) also demands social construction of knowledge. From the above conversation, it can be inferred that the learners interacting inside the topic supports the social construction of knowledge. As the learners were engaged in the dialogue, the fully engaged children construct knowledge that remains in the cognition for a long time.

In our view, the learners had participated very less in the previous classes before the first author used the project-based learning, but when applied PBL in the classroom, we found the learners engaged in active dialogue with friends and the teacher. It might be due to the project used in recent days or due to the opportunity they got to present their understanding in front of all. In the past, we did not remember when we asked students to present on mathematical topics in front of all. We used to come to class and teach a lesson by solving some problems (so-called important) on white-board and asked students to copy them. Before applying the project, they did not get any opportunity to share their understanding about the lesson in front of the classroom, whatsoever, PBL motivated the learner to present their ideas and knowledge in front of all friends and developed the habit of questioning cause and effect of the mathematical procedures.

\section{PBL Stimulates Engaged Learning Through Discovery Learning}

It was the eighth day in the field (8th August 2018), the students of grade IX were solving the problems of the worksheet which was related to the 'slope of the peak'. They were grouped to share their ideas. Each of them was provided with a distinct problem related to the straight-line slope (peak). The first author was mentoring them and observing their activities. They were interacting and having discussion with their friends. In the meantime, one of the children approached the first author and asked, "Sir, my friends decided that they would measure the distance from the base to the top of the peak and find the height using the formula of slope and Pythagoras theorem. But the path we use to climb the peak is not a straight line, how can it be a hypotenuse? Will the length we get be accurate? "The first author thought for a while and asked him "Do you have better ideas than this?" "What if we use the speed of sound to measure that distance, it will be more accurate than this?" He replied "How? " The first author asked. "First, we set two clocks with the same time in hours, minutes and seconds. Then one of the friends will climb the peak and next will stay back to the base. He will shout from the top of the peak at 11:00 a.m. and the person at the base will note the time when s/he hears that sound. As we know the speed of sound, we can find the distance by using the relation; speed = distance travelled over time. What do you think sir?" he looked at me with curious eyes. "It's 
a good idea, but how do you measure the time as the speed of sound is very high in comparison to the distance that we are going to travel? " The first author asked curiously. He paused for a while and replied with expectation, "I will think of it, sir." This event made the first author think about past practices of teaching. In past days, the first author used to enter the class, write the topic on the board straight, immediately afterward start giving a lecture about the topic, illustrate some routine problems, and ask learners to practice similar types of problems. Students rarely asked any questions relating to the topic (Dahal, 2017). They were afraid of asking a question to the teacher, perhaps due to the culture, they grew with where they were supposed to follow each and everything that the senior or elder told them to do (hard control). Their creative thought and reasoning ability was suppressed and lost somewhere in the oblivion. But we came to realize, after using this approach, that the use of project added water to the barren land of their mind. Motivation being the key component of Discovery learning (Thorsett, n.d.), Snigdh, one of the high performers might be motivated through the project under experiment. Or he might be engaged in the learning process that he could relate the learning with his prior knowledge and experiences. According to Bruner (1960), providing varied experiences in a particular field increases effective thinking about the subjects and helps to solve the problems. While a student like Snigdh related the concept of mathematics with the conception of science, he might have been analysing his past experiences with the present experiences and fusing them to find new ideas. The stimulation provided by learners' true experience (practical interest) might be due to the PBL. The first author had not experienced such behaviour from him before. On the next day (9th August 2018), the first author went on a field trip with the students of grade IX and two other co-teachers (Swayambhunath). They were already explained about the objectives of the trip and the plan of activities. After reaching the spot, they divided them into groups and

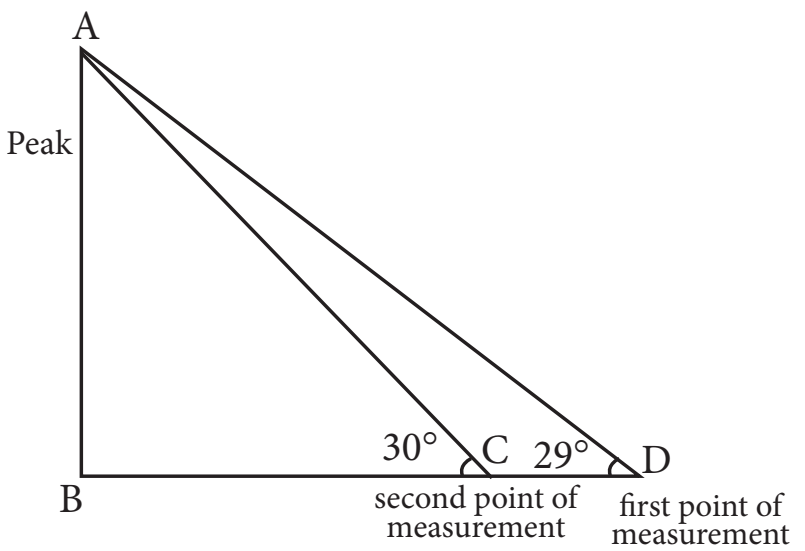
started working according to plan. The first author was observing every group wondering 'how they would accomplish their task'. Suddenly, the first author's eyes fell on the group in which, the same boy (Snigdh) who shared the idea of calculating exact distance, was measuring angles. They used a different idea something like finding distance without measuring from base to peak. The first author inquired about 
the idea he was using to measure the distance. When the first author heard his thoughts, the first author got encouraged with his thinking and ideas of calculation. He used the concept of height and distance, which is in the curriculum of the tenth standard of the Nepal government (CDC, 2017), instead of using the idea of 'slope'. They measured two different 'angles of elevation' from two different points at the base with the same horizon, which was 10 meters apart, as illustrated in the figure above. Then the first author asked him how they would find the height of the peak. He explained that they would solve two different right-angled triangles $\triangle \mathrm{ABC}$ and $\triangle \mathrm{ABD}$ to find the height of the peak.

Then illustrated the solution as shown below:

The angles were found $\theta_{1}=30^{\circ}$ and $\theta_{2}=29^{\circ}$ and let $A B=$ ' $x$ ' meters. So, in triangle $\triangle \mathrm{ABC}, \tan \theta_{1}=\mathrm{AB} / \mathrm{BC}$ gives $\mathrm{BC}=\sqrt{3}$. $\mathrm{x}$ and, in triangle $\triangle \mathrm{ABD}, \tan \theta_{2}=\mathrm{AB} / \mathrm{BD}$ gives $\tan 29^{\circ}=\mathrm{x} /(\mathrm{BC}+\mathrm{CD})$, solving it we get, $\mathrm{x}=138.89$ meters $\approx 139$ meters.

The first author was so satisfied with his methods and later after reaching the top of the peak, the first author shared that idea with other groups as well. Even the other groups were also happy with that idea, the idea they were using to calculate the distance was hectic and difficult. So when they got that idea, they tried it to find the height of the peak from the base of another side of the peak after descending from it. This is one of the best events which the first author noticed on the trip. The students were discovering mathematical knowledge rather than just depositing it in mind, favoring the perspective of the problem posing method by Freire (1993). It is an experimental knowledge which they felt, experienced and practiced in collaboration and cooperation with co-learners. In this case, students constructed knowledge exhibiting the practical interest of Habermas (1972). Similar kinds of data had been analysed on other days as well. In the instance analysed above, learners were directly involved in the learning process for discovering knowledge. During the interview with one of the participants, he shared that "I was so bored of just doing exercise in previous days. This project refreshed me and developed the habit of researching" (Interview, 3rd September 2018). Also, a participant shared that she enjoyed the project as "I got the opportunity to learn mathematics practically. The group-interaction enforced her to think upon the subject and she got the inspiration to investigate at home" (Interview, 25th August 2018). These reflections and information reveal that interaction and active discussion among learners give rise to a better understanding and the practice of constructing knowledge by interaction, which promotes students' engagement in learning mathematics.

This depicts that the learners were highly engaged in constructing knowledge. It also represents that the learners were critically examining their thought process for making meaning. The knowledge construct interest mentioned above is 
directly guided by the practical interest of knowledge construction as explained by Habermas (1972). The learners' prior knowledge, their cultural background, and the learning process they adopted creates their experience, which develops a piece of new knowledge. They get involved in the working process actively which leads to discovery. According to Bruner (1960), learners get highly engaged in the learning process through discovery learning. If the learners get an opportunity to contribute to the learning process, the learning will be more meaningful to them as they get directly involved in the part of learning. they will learn mathematics by learning by doing (Schwartz, 2012), experiencing, and engaging in the learning process. Learners interact, discuss, and argue with each other during the process of discovering knowledge. They might not be able to find the result without collaborating and cooperating with other learners.

\section{PBL Fosters Engaged Learning Through Hands-on Activities}

It was the day of August 2018; the first author went to class with worksheets related to the last trip. Two days before, the first author along with students had been to Swayambhunath temple to find the height of the peak as a part of the project titled "Climbing the sloppy peak is challenging". They had collected the required information and data for further calculation at Swayambhunath. The first author had given five minutes to be ready to solve the problems from the worksheet. Then the worksheet was distributed to each learner. The worksheet included a table with seven rows and nine columns at the front page and reflective questions at the back. The first row contained heading, whereas the remaining rows were for recording the findings of six different groups. The heading in the columns gives a detailed explanation about what they need to record in the trip sheet. In the beginning, the students got engaged in their groups as divided during the trip. The students were divided into six different groups, each having four to five members. They worked accordingly on the trip to collect data and information, measure distance, height, and angle of elevation, and calculate results. After they gathered in their groups, the first author gave them ten minutes to find the result and interact among the group members. All groups started to find the height of the peak, time-taken, and speed of traveler while ascending and descending through the peak. Not only that, but they also measured the slope of the peak taking the basis of a point at the base of the peak. After ten minutes, another five minutes was given to share the ideas among the friends. For that, a new group was formed taking one member from each previous group. Five different groups (new) of five to six members were formed. Each member was provided with a minute time to explain their findings. Then they started sharing the finding and result of their trip one after another. After they finished sharing, all the students got back to their original places. Then they were given the next five minutes 
to write their understanding and reflections about the trip and the activity that they accomplished recently, assuming that reflecting action is one of the purposes of learning (Pant, 2017). They took some additional time, as they were doing the work individually. After finishing the work, the worksheets were collected for observation. The first author took time in the mathematics lab, sitting alone in the cabin, searching for new thoughts and ideas on the students' worksheets. Some of them had written about different interesting moments during the trip and activities they had carried out inside the classroom, some shared the bitter experiences of the trip.

The first author was right there in the classroom while the students were sharing and working with worksheets provided to them. The first author observed a lot of things such as students' behaviour, learning attitudes, time management skills and participation in the interaction. The first author was quietly listening to the students and their conversation with their friends. The first author found enthusiasm in students' behaviours, motivated them to complete the tasks, questioning with friends (Dahal, 2017), explaining, and helping each other for finding the result. Hence, we concluded that this kind of hands-on activity motivated learners to learn mathematical concepts. They constructed knowledge by practicing and interacting with friends as in the practical interest of Habermas (1972) and collaborative learning urged by Carruthes and Worthington (2006), open communication and collaboration appear to be key to developing shared practices and understanding mathematical development.

Besides, the problems included in the worksheet connected mathematics with their life. The problem of finding a participant's speed of ascending peak made them aware of the usefulness of mathematics. The learners, while they were engaged in solving the contextualized mathematics problems, were pleasing. This mode of learning mathematics through practicing and experiencing is as same as the practical interest of knowledge construction (Habermas, 1972) even as emancipatory interest when they critically think and search for possible solutions. Learners constructed mathematical knowledge by sharing, questioning, and thinking critically on the topic. In the interview taken by the first author with one of the participants after the activity shared that, "I had never thought the ideas of optional mathematics also can be applied in our life. I know very few applicability of mathematics from compulsory mathematics curriculum, but I haven't thought about it before" (Interview, 14th August 2018). This participant's claim gives insight that learners' thinking about mathematics had been changed after applying PBL. A child started to link the mathematical conception with his life developing her own understanding of mathematics. This kind of self-realization (emancipatory) is possible when a child is deeply engaged in the learning process and only when a child participates actively 
in the learning process. In this regard, PBL supports learners to be engaged in the learning and meaning-making-process through the hands-on activity as a tool.

\section{Conclusions}

Among many engaging pedagogies, PBL is one of them that engages learners in learning mathematics. During the inquiry, the students were engaged in learning mathematical concepts of coordinate geometry and trigonometry by applying PBL to overcome real classroom problems such as students' demonization and disinterest in learning. And it is found that PBL engaged students in learning mathematics through multiple ways such as questioning, pair/group discussions, discovery learning, concept mapping, and hand-on activities. This study helped understand the effective ways to motivate learners to engage and participate in the learning process. Previously, while lecturing in the class, we as a teacher used to struggle hard to attract adequate attention of the students, but while applying PBL, they have shown interest to engage with their friends for constructing meaning from interaction and discussion. As a mentor in PBL class, our role is to help, share, and support each other in need. It has helped to create a learning environment in class. Similarly, students were also benefited as their burden of mathematics got reduced. They divide and share tasks in the group and opportunities to interact/share during the class. They are not limited to the four walls of schools' classrooms but have begun to explore mathematics in the community/society as well. In sum, this research has helped us reflect upon our teaching and learning style and the nature of learners in mathematics classrooms. We have come to realize that 'every learner has different ability to grasp knowledge and if the teacher uses appropriate pedagogy identifying the real problems of the classroom, learning becomes engaging and meaningful'. Although the selection and development of suitable projects to overcome the existing problems are rigorous, the regular monitoring and updates in the project plan helped to understand the effective ways of energizing the students for learning and making them curious. Nevertheless, this research study has made us aware of the need for a 'pedagogical turn' in teaching and learning mathematics for $21^{\text {st }}$-century learners.

\section{Implications}

This research might be useful in terms of teaching and learning mathematics. All in all, the very first application is for researchers. The findings of the research help to use the varieties of teaching and learning style. It helps to understand the students' perspective about learning mathematics through their reflective journals and motivates them to use appropriate pedagogy for differentiated learners in the classroom. Similarly, the finding might be useful to teacher educators and fellow teachers to engage learners in mathematics learning. Although the usefulness and 
effectiveness of research findings vary based on the different constraints such as academic grades, age group of participants, subject matters, number of learners in the class, nature of the learners and their mental schemas, PBL applies to a large extent for many other similar settings and learning environment. Likewise, the teacher researchers, learners, academicians, and novice teachers might use this research to get the research outline, apply it in the classroom, or use it as a reference for further study. We understand that the research findings do not apply to all conditions. But, if the readers are encountered with similar kinds of problems such as disinterest in learning mathematics, the problem of conceptual understanding, irregularity of home assignment, etc., it may be more effective and eye-opening for them.

\section{References}

BIE. (2018). Why PBL? https://www.bie.org/about/why_pbl

Caram, C. A., \& Davis, P. B. (2005). Inviting student engagement with questioning. https://www.perry.kyschools.us/docs/district/depts/30/questioning.doc

Carruthers, E., \& Worthington, M. (2006). Children's Mathematics: Making marks, making meaning. Paul Chapman Publishing.

Creswell, J. W. (2012). Educational research: Planning, conducting and evaluating quantitative and qualitative research. Pearson Education, Inc.

Dahal, N. (2013). Teacher-student's relationship and its potential impact on mathematics learning: An autoethnographic inquiry [Unpublished Master Dissertation]. Kathmandu University School of Education, Dhulikhel, Nepal.

Dahal, N. (2017). Understanding and usage of questioning by mathematics teachers: A narrative inquiry [Unpublished MPhil Dissertation]. Kathmandu University School of Education, Dhulikhel, Nepal.

Dahal, N. (2020). Teacher-students bonding in mathematics learning: An exploration of past, present, and future. Journal of Mathematics Education, 5(1), 63-76. http://www.assumptionjournal.au.edu/index.php/eJIR/article/view/4402

Dahal, N., Luitel, B. C., \& Pant, B. P. (2019). Understanding the use of questioning by mathematics teachers: A revelation. International Journal of Innovative, Creativity and Change, 5(1), 118-146.

Ernest, P. (2001). Critical Mathematics Education. In P. Gates (Eds.), Issues in Mathematics Teaching. Routledge Falmer.

Freire, P. (1972). Pedagogy of the oppressed. Continuum.

Frerrance, E. (2000). Themes in education: Action research. Northeast and Islands Regional Educational Laboratory, Brown University.

Gardner, H. (2011). Flame of mind. Basic Books, A Member of Perseus Book Group. 
Goodman, B. (2010). Project-based learning. http://www.fsmilitary.org/pdf/Project_ Based_Learning.pdf

Habermas, J. (1972). Knowledge and Human Interests. London: Heinemann Educational.

Kemmis, S., \& Wilkinson, M. (1998). Participatory action research and the study of practice. Action research in practice: Partnerships for social justice in education, 21-36.

Krajcik, J. S., \& Blumenfeld, P. C. (2006). Project-based learning. In R. K. Sawyer (Ed.), Cambridge handbook of the learning sciences (pp. 317-333). Cambridge University Press.

Le, N. T., \& Huse, N. (2016). Evaluation of the formal models for the Socratic methods. https://www.researchgate.net/30159116

McNiff, J., \& Whitehead, J. (2006). All you need to know about action research. Sage Publication.

Moursund, D. (1999). Project-based learning using information technology. Eugene, International Society for Technology in Education.

Pant, B. P. (2015). Pondering on my beliefs and practices on mathematics, pedagogy, curriculum and assessment [Unpublished MPhil dissertation]. Kathmandu University School of Education, Lalitpur, Nepal.

Pant, B. P. (2017). Doing, teaching, learning and thinking about mathematics - on becoming a transformative teacher. Journal of Education and Research, 7(1), 11-24. doi:http://dx.doi.org/10.3126/jer.v7i1.21237

Quist, M. (2018). What is project-based learning for math? https://study.com/ academy/lesson/project-based-learning-for-math.html

Stringer, E. T. (2007). Action research. Thousand Oaks, California: Sage Publications, Inc.

Taylor, P. (1998) Constructivism: Value Added, In B. Fraser \& K. Tobin (Eds), The International Handbook of Science Education (pp. 12-20). Kluwer Academic

Thomas, J. W. (2000). A Review of Research. The Autodesk Foundation.

Tyata, R. K. (2018). Project-based learning for engaging students in Mathematics [Unpublished Master Dissertation]. Kathmandu University School of Education, Dhulikhel, Nepal.

Yeh, C. Y. C., Cheng, H. N. H., Chen, Z. H., Liao, C. C. Y., \& Chan, T. W. (2019). Enhancing achievement and interest in mathematics learning through MathIsland. Research and Practice in Technology Enhanced Learning, 14(1). https:// doi.org/10.1186/s41039-019-0100-9. 